\title{
The role of taxonomies in the study of human memory
}

\author{
DANIEL B. WILLINGHAM and KELLY GOEDERT \\ University of Virginia, Charlottesville, Virginia
}

\begin{abstract}
The idea that memory is not unitary but is instead composed of multiple systems has a long history and has been debated with particular vigor in the last 20 years. Nevertheless, whether or not there are multiple memory systems remains unsettled. In this article, we suggest that psychologists wishing to classify memory can learn from biological systematics, the discipline that creates taxonomies of species. In so doing, we suggest that psychologists have made two assumptions in classifying memory: that features of memory are perfectly correlated, and that there is a straightforward mapping between taxonomy and theory. We argue that these assumptions are likely to be incorrect, but we also argue that there is a place for taxonomy in the study of memory. Taxonomies of memory are organizational schemes for data - they are descriptive, not explanatory - and so can inspire theory, although they cannot serve as theories themselves.
\end{abstract}

During the last 20 years, there has been intense scrutiny of the idea that human long-term memory may be composed of separate systems. There has been debate about the definition of "system," about the number of putative systems, and about the features that distinguish them (see Foster \& Jelicic, 1999, and Schacter \& Tulving, 1994a, for a number of different perspectives). Despite the intense scrutiny, consensus on the most basic question - are there multiple systems of long-term memory?-has eluded us.

We suggest that researchers have not reached consensus because two critical assumptions have been made in this research, and these assumptions have not been examined. First, in creating multiple memory systems proposals, researchers have assumed that features of memories are perfectly correlated. In other words, they have assumed that a memory with one feature, such as the fact that it relies on the hippocampus, will necessarily have other features, such as being associated with awareness. Second, when evaluating multiple memory systems proposals, researchers have assumed that they can be mapped to theories of memory in a one-to-one fashion. In other words, they have treated classification schemes for memory as de facto theories of memory.

Although other factors have contributed to debate about memory systems (such as what the criteria should be in postulating new systems; e.g., Nadel, 1994; Nyberg \& Tulving, 1996), we contend that a memory systems proposal

This work was supported by NIH Grant RO1 NS40106-01 and NSF Grant BRS9905342. The authors thank John Jonides and two anonymous reviewers for helpful comments on an earlier draft. Correspondence should be addressed to D. B. Willingham, Department of Psychology, University of Virginia, 102 Gilmer Hall, Box 400400, Charlottesville, VA 22904 (e-mail: willingham@ virginia.edu). that gains common acceptance is impossible, so long as these assumptions are made. We point to work in biological systematics to argue that these assumptions are unlikely to be correct, and we consider a new role for classification systems in memory research.

\section{BACKGROUND}

\section{The Impetus for Multiple Memory Systems Proposals}

The history of multiple memory systems proposals is well known to students of memory, and so we will summarize only that part of the history that is relevant to the creation of systems proposals (see Gabrieli, 1998, and Schacter, 1987, for more detailed treatments). ${ }^{1}$

During the 1960s, there were occasional reports of patients with dense anterograde amnesia learning some motor skill tasks (e.g., Corkin, 1968). In the 1970s, it was demonstrated that they showed normal repetition priming (Warrington \& Weiskrantz, 1970), and other tasks were soon added to the list (for a review of this early work, see Stern, 1981). During the 1970s, theories that sought to account for these data might be described as "missing process" theories. Researchers assumed that there was a single memory system and that anterograde amnesia compromised one process in this system. This missing process presumably devastated recognition and recall but was unnecessary for successful performance of motor skill and repetition priming tasks, and, thus, amnesics learned them normally. The question, then, was what mnemonic process, when damaged, would lead to the pattern of spared and impaired performance shown by amnesics? Proposals in this vein suggested that amnesics might show poor encoding (Cermak $\&$ Reale, 1978), poor retrieval (Warrington \& Weiskrantz, 1970), poor utilization of cues (Winocur, 1982), or unusu- 
ally fast forgetting (Huppert \& Piercy, 1982). None of these hypotheses met with sustained success.

Towards 1980, researchers began to entertain a different explanation, suggesting that there were two separate systems of memory, only one of which was damaged in amnesia (Cohen \& Squire, 1980; O' Keefe \& Nadel, 1978). We use the terms declarative and nondeclarative because this is one of the better known proposals (Squire \& ZolaMorgan, 1991; this distinction is based on an earlier distinction suggested by Cohen \& Squire, 1980). The declarative system relies on the medial temporal lobe, supports memory for facts and events, and is damaged in amnesic patients. Nondeclarative memory is independent of the medial temporal lobe, supports skills, and is intact in amnesic patients. A number of proposals along these lines were made in the $1980 \mathrm{~s}$, most of them difficult to distinguish from one another empirically (for a review of work from this period, see Hirst, 1982). Thus, the initial impetus for separating memory into systems was to explain a pattern of data.

Multiple memory systems were proposed to account for the pattern of data shown by amnesic patients-the pattern called an anatomic dissociation, in which neurologically impaired patients show impaired performance on some tasks and intact performance on other tasks. During the 1980s, researchers also sought evidence from neurologically intact participants that would support the multiple memory systems proposals. Two analytic techniques were important in this effort: functional dissociations, and stochastic independence. A functional dissociation is demonstrated if two tasks (each thought to tap a different memory system) are differently affected by an independent variable. For example, deep encoding instructions were shown to enhance recall, but not priming (Jacoby \& Dallas, 1981). The idea is that if two tasks are supported by the same memory system, then an independent variable will necessarily affect performance of the two tasks in the same way. If it does not, this indicates that the tasks are not supported by the same system. This pattern of results is called a single dissociation-one task is affected by an independent variable whereas the other is not-and it is open to an alternative interpretation. A single system may underlie both tasks, but the tasks may differ in difficulty. Stronger evidence for multiple systems is a double dissociation, in which one task is affected by an independent variable, and the other task is affected in the opposite way (Dunn \& Kirsner, 1988).

Stochastic independence is measured by administering a single encoding episode and then administering two retrieval tests, each thought to tap a different memory system. Stochastic independence uses an item-by-item analysis to evaluate the likelihood that an item will be retrieved on one test, given that it was or was not retrieved on the other test. If a single system supports performance of the two tasks, one would expect that success in retrieving an item on one test will mean that it is more likely that the item will be retrieved on the other test. If separate memory systems support performance on the two tests, one would expect that success on one test will not be predictive of suc- cess on the other test - that is, stochastic independence will be observed (e.g., Tulving, Schacter, \& Stark, 1982).

In the late 1980 s and early 1990 s, researchers began to fractionate memory still further. They demonstrated anatomic dissociations among different varieties of nondeclarative memory (e.g., Heindel, Salmon, Shults, Walicke, \& Butters, 1989; Keane, Gabrieli, Fenneman, Growdon, $\&$ Corkin, 1991) and proposed that nondeclarative memory and declarative memory were themselves composed of multiple systems (Tulving \& Schacter, 1990). By 1994, Schacter and Tulving (1994b; see also Schacter, Wagner, \& Buckner, 2000) proposed that there were at least five memory systems, and Squire and Zola-Morgan (1991) proposed that there were seven.

\section{Criticisms}

Also during the late 1980s and early 1990s, the multiple memory systems enterprise came under heavy criticism. Some criticism suggested that the reported dissociations were not well supported by the data. For example, Ostergaard (1999; Ostergaard \& Jernigan, 1993) suggested that amnesic patients might actually be impaired, not intact, in learning nondeclarative tasks; he argued that previous studies had lacked the statistical power to detect such an impairment. Shanks (Shanks \& Johnstone, 1999; Shanks \& St. John, 1994) and Perruchet (Perruchet \& Amorim, 1992; Perruchet, Bigand, \& Benoit-Gonin, 1997) suggested that the main functional dissociation in normal subjects - that nondeclarative memory could be acquired outside of awareness - had not been satisfactorily demonstrated. They outlined problems in the design of previous experiments and suggested criteria that would have to be satisfied before one accepted that unconscious learning had taken place.

Others criticized the logic of multiple memory systems proposals. Some charged that the definition of systems was circular: The fact that amnesic patients are intact on nondeclarative memory tasks and impaired on declarative memory tasks is supposed to provide evidence for the distinction between those systems, but they charged that declarative memory is defined as anything that amnesic patients cannot learn (Ostergaard \& Jernigan, 1993; Ratcliff \& McKoon, 1996).

It was also shown that the dissociation techniques applied to data from normal subjects were faulty. Findings of stochastic independence could be the result of insufficient statistical power to detect dependencies. Poldrack (1996) showed that 1,600 subject items are needed to provide $80 \%$ power to detect moderate dependence, and most studies have not used that many items. Hintzman (1990) pointed out that what appears to be stochastic independence may in fact be a statistical artifact, and Shimamura (1985) noted that measuring stochastic independence requires at least two tests, and carryover effects between the tests could cause spurious dependence or independence (for a review of such problems, see Howe, Rabinowitz, \& Grant, 1993).

Functional dissociations are no more reliable than stochastic independence as a guide to separate memory sys- 
tems. If two tasks are indeed different (e.g., vary on some independent variable), then there likely is not complete overlap in the cognitive processes recruited to complete them. Therefore, it should not be surprising that one can find an independent variable that affects the two tasks in different ways because the tasks involve different processes within the same memory system - that is, a functional dissociation (Hintzman, 1990; Neely, 1989). Another problem is that experimenters typically use experimental conditions that sample just two levels of the range that independent variables might take in the experiment. Depending on which part of this range is sampled, a spurious double dissociation could be observed (Olton, 1989). Furthermore, researchers suggested that the observed behavioral dissociations could be accommodated within existing principles of memory, especially transfer appropriate processing. They pointed out that the behavioral dissociations often entailed one type of training (putatively tapping one system) and then failure to observe transfer to a different test (putatively tapping a different system). The failure to observe transfer could be due to the change in tests between training and transfer, without recourse to different systems. Blaxton (1989) offered a compelling empirical test of an alternative processing account of some priming effects that had been attributed to different systems.

Anatomic dissociations also do not compel a separate systems account. Just as one would not expect complete overlap in the cognitive processes supporting two different tasks, wouldn't one expect that any two nonidentical tasks will have some nonoverlapping areas of the brain supporting their performance, thus offering the chance to see an anatomic dissociation (Roediger, Rajaram, \& Srinivas, 1990)? In extremis, might we not end up with a "banana memory system" and a "plum memory system," should separate pools of neurons support those concepts (Roediger, Buckner, \& McDermott, 1999)?

Furthermore, there is no reason to assume a direct mapping between cognitive structures and brain structures (e.g., Weldon, 1999); in other words, memory may be supported by separate brain structures, but those brain structures may use the same processes and representations to support memory at a cognitive level of description. One could draw an analogy to a computer hard drive: If two Microsoft Word documents occupy different parts of a computer's hard drive, does that indicate that there is a fundamental difference between them? No, because the representation format and the processes (i.e., software) needed to interpret the two files are the same, despite their different "anatomic loci." By the same token, Microsoft Word and Microsoft Excel documents would be considered different, even if they occupied neighboring or even interleaved portions of the hard drive, because they use different formats and because different processes are required to interpret them. We could apply the same logic to memory. Anatomic separability is not enough. There must be a difference between the representations at a cognitive level of description to draw the conclusion that they are truly different and represent sep- arate memory systems. We draw this conclusion because we assume that cognitive psychologists want to develop models at a cognitive level of description. Ultimately, anatomic separability may hold the promise of likely cognitive separability, but it does not guarantee it.

The criticisms of the logic by which multiple memory systems were defined seemed potent. By the early 1990s, it appeared that it was so easy to find cognitive and anatomic dissociations that the multiple systems approach was spinning out of control, with new memory systems popping up like daisies. One could argue that there is nothing in principle wrong with the postulation of new systems; the reality may simply be that there is a large number of memory systems (Gabrieli, 1999). On the other hand, Occam's razor dictates that the simplest successful explanation of the extant data is the preferred explanation, and postulating more systems if fewer will do is unnecessarily complex. The core problem seemed to be a lack of clarity regarding what constituted evidence sufficient to propose a new system and correspondingly little attention to what was really meant by the word system (Roediger, 1990; Roediger et al., 1990).

\section{Response to Criticisms}

The response to these criticisms was to clarify the definition of system and to propose more stringent criteria by which a system could be identified (e.g., Nadel, 1994; Nyberg \& Tulving, 1996; Schacter \& Tulving, 1994b). The researchers who supported the multiple memory systems approach suggested that multiple criteria would have to be satisfied before a new system would be proposed, rather than relying on a single anatomic dissociation or the simple observation of stochastic independence. These criteria spanned different characteristics of memory, including their anatomic basis, the function they served, their developmental course, their pharmacological basis, and so on. A summary of the criteria in various proposals appears in Table 1.

Making the criteria more stringent served two purposes. First, it employed the logic of converging operations. Individual criteria (e.g., anatomic dissociation) might not be trustworthy, but if multiple dissociations across different aspects of memory all pointed to the same set of systems, then presumably that pattern of data was reliable (Nyberg \& Tulving, 1996; Schacter, 1992). As reflected in Table 1, different researchers deemed different types of dissociations to be the critical ones and required a different number of dissociations to be observed before a new system would be proposed. Second, it guarded against the runaway proliferation of memory systems. For example, an anatomic dissociation was not enough to warrant separate banana and plum memory systems because such "systems" would not serve different purposes, nor would they have different developmental courses, and so on. In point of fact, turning to multiple criteria was a significant problem; we explain why in a later section.

The debate over multiple memory systems is ongoing (Tulving, 2000). Researchers examining the large database 
Table 1

Proposed Criteria for Differentiating Memory Systems

\begin{tabular}{|c|c|c|c|c|c|c|c|c|}
\hline Citation & $\begin{array}{c}\text { Anatomic } \\
\text { Differences }\end{array}$ & $\begin{array}{l}\text { Function } \\
\text { of System }\end{array}$ & $\begin{array}{c}\text { Processes and } \\
\text { Representations }\end{array}$ & $\begin{array}{l}\text { Developmental } \\
\text { Differences }\end{array}$ & Pharmacology & $\begin{array}{c}\text { Functional } \\
\text { Dissociation }\end{array}$ & $\begin{array}{c}\text { Stochastic } \\
\text { Independence }\end{array}$ & $\begin{array}{c}\text { Length of } \\
\text { Storage Time }\end{array}$ \\
\hline $\begin{array}{l}\text { Cohen \& Eichenbaum } \\
\text { (1993) }\end{array}$ & $X$ & & $X$ & & & & $X$ & \\
\hline Nadel (1994) & $\mathrm{X}$ & & $\mathrm{X}$ & & & & & $X$ \\
\hline $\begin{array}{l}\text { Nyberg \& Tulving } \\
\text { (1996) }\end{array}$ & $\mathrm{X}$ & & $\mathrm{X}$ & $\mathrm{X}$ & $\mathrm{X}$ & & & \\
\hline $\begin{array}{l}\text { Roediger et al. } \\
\text { (1990) }\end{array}$ & $X$ & & X & & & $X$ & $X$ & \\
\hline $\begin{array}{l}\text { Schacter \& Tulving } \\
\text { (1994b) }\end{array}$ & $\mathrm{X}$ & & $X$ & & & $X$ & & \\
\hline $\begin{array}{l}\text { Sherry \& Schacter } \\
\quad(1987) \\
\text { Squire (1992) } \\
\text { Tulving (1984) }\end{array}$ & $\begin{array}{l}X \\
X \\
X\end{array}$ & $\mathrm{X}$ & $\mathrm{X}$ & X & & & & \\
\hline
\end{tabular}

of experimental results from the last 20 years draw opposing conclusions, ranging from certainty that multiple memory systems exist (Gabrieli, 1999; Tulving, 1999), to the suggestion that there are no memory systems as such (Ratcliff \& McKoon, 1996; Toth \& Hunt, 1999), to the proposal that the field has moved past the question altogether (Blaxton, 1999; Roediger et al., 1999).

\section{ASSUMPTIONS MADE IN MULTIPLE MEMORY SYSTEMS PROPOSALS}

We suggest that two assumptions have been made in this debate, by both the boosters of multiple memory systems and their critics. Neither assumption is supportable, and in fact both are likely to be incorrect.

Assumption 1: Features of memory are correlated. This assumption was made as researchers constructed multiple memory systems proposals. When researchers describe memory systems, they sort memories into categories. This sorting is based on features of the memories. For example, a memory might rely on the hippocampus for its normal functioning, or it might not; "reliant on the hippocampus" is a feature that can take on two values: yes or no. We might define Memory System 1 as handling memories with a set of features: for example, "relies on the hippocampus," "associated with awareness," and "can be applied in different contexts." But how would one categorize a memory that has two of these features but lacks the third? To this point, researchers have assumed that features will be correlated, and that if features seemed not to be correlated, that constituted evidence against a particular memory system proposal.

Assumption 2: The mapping from classification system to theory will be one-to-one and will be straightforward. This assumption was made as researchers evaluated multiple memory systems proposals. This is the assumption that once a classification system has been described, it can be used as a broad, if vague, theory, or at least that the taxonomy will constrain theories that one might propose. We will argue that this assumption is not true. Taxonomies cannot be considered vague theories; taxonomies are not theories that explain data but rather are descriptions of data. We will also argue that taxonomies cannot significantly constrain theories, because a single theory can give rise to multiple taxonomies - we provide an example of this using the theory of evolution and taxonomies of species. Furthermore, the manner in which a theory such as evolution plays out in a taxonomy of species can be quite complex, meaning that observing the taxonomy would not be of much help in deducing the theory. Finally, we argue that a theory is actually a prerequisite to developing a taxonomy; thus, a taxonomy cannot be of help in deducing a theory.

We consider each of these assumptions in turn.

\section{Assumption 1: Features of Memory \\ Are Correlated}

Multiple memory systems proposals are based on the classification of memory. All of these proposals sort memories into classes, such as nondeclarative/declarative (Cohen \& Squire, 1980), episodic/semantic (Tulving 1972, 1983), and so on. Classification is based on the similarity of features. Entities to be classified have features-for example, animals have features such as "possesses a backbone" or "suckles its young." A researcher observes the entities and sorts them into groups on the basis of the similarity of their features (Mayr, 1942; Simpson, 1961). For example, all animals that have a backbone are classified into one category, and those without a backbone are sorted into another category.

Memories may be described as having features-for example, whether or not a memory depends on the medial temporal lobe, whether or not it contains personal information, and so on. These features need not be binary. One could say that a particular memory may not be susceptible to interference, minimally susceptible, or very susceptible. (If the features are to take on continuous values, a dimensional classification becomes appropriate in which memories are not categorized but are localized in a taxonomic space. That approach has not been used and will not be discussed here.) Thus, a researcher must select relevant features that define classes (e.g., "depends on the hippocam- 
pus," "depends on the striatum," "other") and then describe rules by which an entity can be reliably assigned to a class. For example, if functional imaging results consistently show hippocampal activation associated with a task, but hippocampal damage does not compromise task performance, does the memory that supports task performance depend on the hippocampus?

What is noteworthy about current multiple memory systems proposals, as shown in Table 1, is that they use multiple features to define systems. This practice relies on the assumption that features will be perfectly correlated. If they are not, there will be memories that are not classifiable. For example, how would one classify a memory if it depended on the integrity of the hippocampus but was not associated with awareness (Chun \& Phelps, 1999)? What happens when the classifications guided by different features conflict?

One could argue that such conflicts indicate that the classification is not correct and needs to be refined. We will argue that this approach is not tenable, because it assumes that there is a single set of memory systems to be discovered in nature (i.e., one way to describe memory systems). There is no evidence to support this assumption, and there is good reason to suppose that it is not true. The problem lies in the fact that moderately complex entities offer more than one organizing principle on which to select features. We might call such an organizing principle a conceptual basis for a classification. For example, one conceptual basis might be neuroanatomy, meaning that the features used to classify memories would be neuroanatomic. A different conceptual basis would be "information processing characteristics" in which the researcher would select features of memory at a cognitive level of description (e.g., "probability of retrieval improved by deep processing"). Each conceptual basis may itself be valid, but it need not agree with other, equally valid conceptual bases.

In fact, conceptual bases are likely to conflict. Consider the history of biological systematics. Until the 20th century, taxonomies of species were based on the similarity of species' appearance. Appearance was used because it seemed obvious that a formal taxonomy should more or less respect people's folk taxonomies; thus, birds all belonged in one family because they look alike, crocodiles should be fairly close to lizards for the same reason, and so on. In the 20th century, researchers began using evolution as the conceptual basis of taxonomies; a taxonomy should represent the results of evolution, in the form of a hierarchical tree. Shared ancestry was represented in the vertical dimension of the tree, and the similarity of species' adaptations (as revealed by the physical characteristics of the organisms) was represented in the horizontal dimension, as shown in Figure 1. This type of taxonomy is called evolutionary taxonomy (Mayr, 1969).

The problem with this scheme is that the classification seeks to simultaneously use two conceptual bases, and these two bases can conflict. Two species that do not share a recent common ancestor may nevertheless look similar, due to adaptive pressures. For example, birds and crocodiles share a more recent common ancestor than do lizards and crocodiles, but lizards and crocodiles share more physical characteristics, as shown in Figure 1 (Ridley, 1986).

In order for a taxonomy using more than one conceptual basis to be internally consistent, the two conceptual bases must not conflict. The likelihood that all of the characteristics in Table 1 are correlated seems low, given that there is already evidence of conflict. Two examples are shown in Figure 2. Amnesic patients show impaired performance on free recall tasks (Graf, Squire, \& Mandler, 1984) but are unimpaired in stem completion (Graf et al., 1984) and learn normally on the serial response time (SRT) motor sequencing task (Nissen, Willingham, \& Hartman, 1989; Reber \& Squire, 1994). Thus, using an anatomic criterion, stem completion priming should be closer to the serial response time task than to free recall. A pharmacological criterion, however, leads to a different conclusion. Lorazepam impairs free recall and stem completion priming while leaving SRT performance unimpaired (Knopman, 1991, Experiment 1), indicating that stem completion priming should be closer to free recall.

Another example of conflicting principles may be seen in comparing classification systems based on development versus computational principles. Children show normal
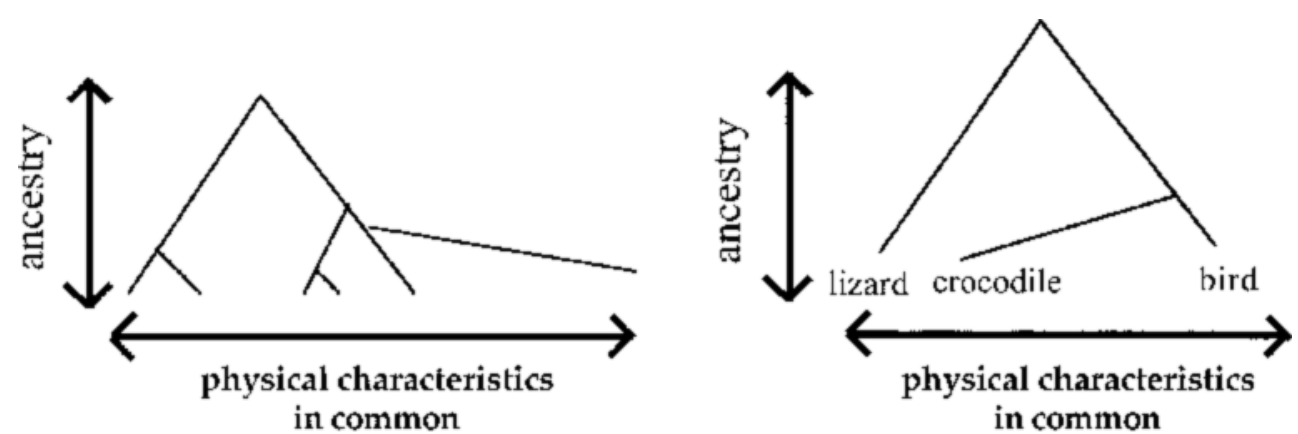

Figure 1. The left panel shows a typical tree diagram used in evolutionary taxonomy. Similarity in terms of physical characteristics is shown in the horizontal dimension, and similarity in terms of the recency of a common ancestor is shown in the vertical dimension. The right panel shows an example of how these dimensions can conflict. Crocodiles share more physical features with lizards but share a more recent common ancestor with birds. 

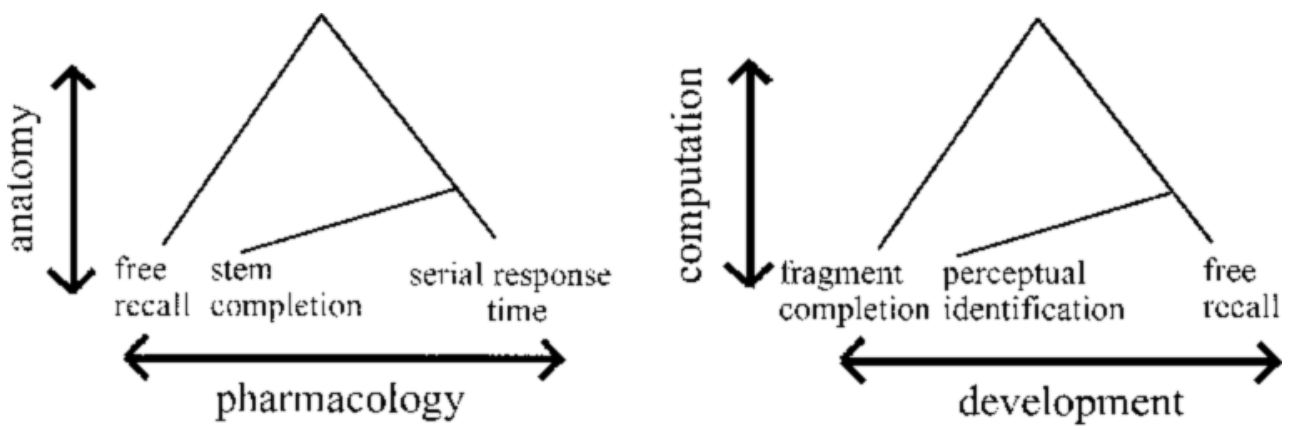

Figure 2. Examples of how dimensions can conflict in classification systems of memory. Stem completion has pharmacological features in common with free recall but has anatomic features in common with the serial response time task. Perceptual identification has developmental features in common with fragment completion but has computational features in common with free recall.

levels of fragment completion priming (Naito, 1990) and perceptual identification priming (Hayes \& Hennessy, 1996) but show impaired free recall performance relative to adults (Russo, Nichelli, Gibertoni, \& Cornia, 1995). Level of processing, on the other hand, affects fragment completion priming (Challis \& Brodbeck, 1992) and free recall (Craik \& Tulving, 1975) but does not affect perceptual identification (Jacoby \& Dallas, 1981).

The most reliably associated features seemed to be that memories that rely on the hippocampal formation are associated with awareness. Now an exception to even that consistent rule has been noted (Chun \& Phelps, 1999).

We suggest that these data are indicative of a more general trend. It is not the case that observing memories that do not fit a taxonomic scheme simply means that the taxonomy must be revised. Complex entities like memories offer many features on which one might classify. These features are rooted in different conceptual bases, and the classifications afforded via the different conceptual bases may all be valid to certain purposes, but they need not be perfectly correlated, and, in fact, likely are not. Therefore, we argue that such conflicts are inevitable when one uses more than one conceptual basis, as most current taxonomic schemes do. Setting "converging dissociations" as a desired or necessary feature of taxonomies (Nyberg \& Tulving, 1996; Schacter, 1992) means that the taxonomy is destined to be internally inconsistent.

If the conceptual bases are correlated imperfectly, couldn't one drop the demand that the correlation be perfect? Perhaps classes could be defined by family resemblance, with no single feature being necessary for class membership. This option was tried in evolutionary taxonomy, but it failed. Conflicts were still observed and had to be resolved by weighting the characteristics representing each conceptual basis. There was, however, no theoretically defensible basis on which to select the weights. Simpson (1961), a proponent of this method, wrote the following: "Taxonomy is a science but its application to classification involves a great deal of human contrivance and ingenuity, in short, of art. In this there is leeway for per- sonal taste, even foibles" (p. 107). Evolutionary taxonomy was therefore criticized for its subjectivity (e.g., Sneath \& Sokal, 1973; Sokal \& Sneath, 1963).

The upshot is that moderately complex entities (such as species or memories) have multiple features and therefore also have multiple ways in which they can be classified. Note that these multiple viable classifications are not simply a human construction. It is not the case that there is one true organization in nature, but human ingenuity leads us to view the organization of species in different ways and, hence, confuse ourselves. We cannot "carve nature at the joints" in Plato's colorful phrase, because nature does not have one set of joints. Different taxonomies are appropriate depending on which aspect of nature one is trying to capture - that is, the purpose of the taxonomy. There is not a single classification of nature because nature has many facets, and a single taxonomy cannot capture them all. Different taxonomies describe different aspects of nature and therefore serve different purposes.

Even a single purpose-describe evolution-can lead to multiple taxonomies, because evolution affects species features through more than one mechanism. These effects lead to different organizations. Evolution usually results in species that share a recent common ancestor also sharing common physical features due to the inheritance of features, but sometimes they share physical features because they have adapted to the same niche, as in the case of cetaceans and fish. Two different aspects of evolution (inheritance and adaptation) yield the same result (similarity of features), and, therefore, fish and cetaceans, which are far apart on one feature (phylogenetic ancestry), are close on the other (physical features). In the case of memory, we can observe similar conflicts in the classification systems, but we do not yet understand memory well enough to know why these conflicts occur.

What are we to take from these phenomena? In biological systematics, the solution was to create taxonomies based on a single conceptual basis, so that conflicts could not arise. One group-numerical taxonomists-used physical appearance, and another group-cladists—used 
ancestral history. Numerical taxonomists sought to exclude evolution altogether from classification (Sokal \& Sneath, 1963). They argued that classification should be completely objective, and for that goal to be met, all theory (including evolution) should be expunged from classification. Cladists, on the other hand, argued that classification of species should not be atheoretical but should reflect at least some of the results of evolution, and they argued that classifications should be based on common ancestry: Species sharing a more recent common ancestor should be grouped together, regardless of whether they share physical features (Baum \& Larson, 1991; Estabrook, 1972; Hennig, 1966; Wiley, Siegel-Causey, Brooks, \& Funk, 1991; but see Platnick, 1980, for an argument that cladistics should be atheoretical).

What of memory? Internal consistency of a classification system seems more a necessity than a luxury. One must be able to use a classification scheme to reliably assign any novel entity (memory) to a class. Memory researchers might do well to follow the example of researchers in biological systematics and create classification schemes using only one conceptual basis. In a later section, we consider this problem more closely.

\section{Assumption 2: The Relationship of Taxonomy and Theory Is One-To-One}

A taxonomy and a theory are not the same thing. A taxonomy is a systematic sorting of objects into groups based on their relationships, usually relationships of similarity (Simpson, 1961). A theory may be defined as an integrated set of principles that explain and predict patterns of data. A taxonomy is a way to organize data; a theory is meant to explain and predict data.

Multiple memory systems proposals have occupied a twilit world between taxonomy and theory. On the one hand, they appear to be taxonomies, in that they are organizations of data; researchers describe characteristics of memories, and on the basis of these characteristics, they sort them into groups. Indeed, some researchers have referred to their proposals as classifications or taxonomies (Robbins, 1996; Schacter \& Tulving, 1994b; Squire, 1992; Tulving, 1985). On the other hand, multiple memory systems proposals are meant to offer predictions and explain data, which are functions of theories. Indeed, the initial and an ongoing impetus of multiple memory systems proposals is to explain neural and behavioral dissociations. Memory tasks vary in their performance characteristics and in their neural bases because they are supported by different memory systems; memory systems proposals serve an explanatory function, as they are offered as explanations of these dissociations.

Furthermore, critics have treated classification systems as theories, criticizing them for only weakly fulfilling the explanatory function and for making only vague predictions (e.g., Blaxton, 1989; Green \& Shanks, 1993; McKoon \& Ratcliff, 1995; Ratcliff \& McKoon, 1995; Roediger et al., 1990). These criticisms have been countered with claims that classification systems do serve these functions (e.g., Gabrieli, 1999; Schacter \& Cooper, 1995). Thus, it is clear that researchers have expected classification systems to fulfill at least some of the functions of theories. Still, they are not complete theories of memory, since although they identify components of memory (each component being a system), they do not seek to explain the workings of these components.

Why is it important to specify whether multiple memory systems proposals are theories or taxonomies? Because theories and taxonomies are not the same thing, and the relationship between them can be complex. We contend that classification systems of memory have been treated as though they mapped directly to theory. Once the classes are defined (e.g., depends on the medial temporal lobe/does not depend on the medial temporal lobe), researchers have treated those classes as theoretical memory systems, with a few exceptions. ${ }^{2}$

In the previous section, we described the complex relationship between the theory of evolution and taxonomies of species and emphasized that this single theory can lead to more than one viable taxonomy. A taxonomy that is meant to capture the results of evolution is not itself a theory of evolution. A taxonomy of memory that is meant to capture anatomic or functional regularities of memory is not a theory of memory. In the case of evolution, the relationship of theory to taxonomy is one-to-many; a single theory yields multiple taxonomies. This state of affairs might make us optimistic: If we can discover multiple taxonomies, all spawned from the same theory, might not examination of these taxonomies help us to zero in on the theory? Perhaps. But, in the case of evolution, where the theory is fairly well understood, the manner in which the processes of evolution yielded the eventual groupings of species was not straightforward. If we had not started with a knowledge of how evolution worked, it is far from obvious that we would have deduced it by examining the taxonomies.

But, more important, the theory is vital to creating the taxonomy in the first place. The chief school of classification that attempts to capture the results of evolution in a taxonomy is cladistics, and it uses techniques that rely on assumptions of evolutionary theory (e.g., de Pinna, 1991; Maslin, 1952; Remane, 1952, cited in Brady, 1985). In other words, cladistics cannot proceed in the absence of evolutionary theory; it's not the case that classification serves as a springboard for theory.

Indeed, one of the lessons that psychologists can draw from observing work in biological systematics is that it is not possible to construct classification systems of memory without making assumptions. Recall that evolutionary taxonomy sought to use two conceptual basesphysical appearance and phylogentic ancestry-and the inevitable conflicts between these two bases led researchers to use "personal taste" to resolve the conflicts. This lack of objectivity led other researchers to seek a system of classification that was completely devoid of theory or assumptions, and so was born the classification approach called phenetics, or numerical taxonomy (Sokal \& Sneath, 
1963). To ensure objectivity, numerical taxonomists used cluster analysis to determine objectively the "distance" between species and to identify the natural groupings into which they fell. It was quickly noted, however, that numerical taxonomy was no more objective than evolutionary taxonomy (Johnson, 1970). First, there are multiple statistical methods of measuring distance among species and of determining what constitutes a cluster. The outcome of the taxonomy could be quite different depending on which of these statistical methods one selected, and there did not seem to be a principled way to select among them.

A second problem applies not only to the phenetic method but to all attempts at atheoretical classification. Each organism has so many characteristics that it is impossible to evaluate each and every one of them. The researcher is forced to discard some characteristics before the analysis begins because it simply is not feasible to include them all. How is the researcher to decide which characteristics to include and which to exclude in the analysis? The researcher must make assumptions about which characteristics are important. Obviously, a theory may serve as the inspiration for these assumptions. Thus, a theory may support the development of a taxonomy, but it is highly unlikely that a taxonomy could provide direct constraints on a new theory.

Memory researchers have, in a sense, already been through a phase of research similar to numerical taxonomy. The attempts in the 1980s to simply follow cognitive dissociations where they led and let those dictate the number and variety of memory systems seem to be in the same atheoretical spirit as numerical taxonomy. Memory researchers abandoned this plan because it became clear that it was simply too easy to obtain dissociations. Memories differed in so many ways that dissociations were simple to obtain, and there was no way of differentiating the theoretically important and unimportant dissociations. This strategy failed for exactly the reason that numerical taxonomy failed. In numerical taxonomy, species differed in many ways, and there was no telling which differences were the crucial ones, and there was no possibility of considering them all. Memories differ in many ways (i.e., have many features), and, therefore, dissociations are easy to obtain; dissociations are the norm (Kolers \& Roediger, 1984).

What are we to conclude from the foregoing discussion? First, taxonomy and theory are not identical, and the relationship between them can be complex. For example, in the case of the evolution of species, different forces of evolution (inheritance and adaptation) can have similar or divergent effects on the characters of species. This means that a researcher seeking to develop a taxonomy based on a feature (e.g., most recent common ancestor) must account for the complex forces of evolution that conflate inheritance and adaptation. In short, although the theory of evolution is fairly well understood, the way it affects features is complex, and it is the features that are the raw material for the taxonomy.
Second, the relationship between taxonomy and theory need not be one-to-one. In evolution, a single theory yields multiple possible taxonomies. This implies that developing taxonomies will do little to constrain theories.

Third, it is not possible to develop a taxonomy in the absence of assumptions - assumptions that are usually guided by a theory that will dictate which features are important to include in the taxonomy. This conclusion also casts doubt on the likelihood that a taxonomy will constrain a theory.

Fourth, we conclude that the "memory systems debate" has been misguided. This debate refers to whether memory is best conceptualized as being composed of multiple, independent systems or whether the data are best accounted for by differences in mnemonic processes. A third, compromise view was also offered: the components processing view (Moscovitch, 1994; Moscovitch \& Umiltà, 1991; Roediger et al., 1999). In this view, memory is composed of a number of processing components that are recruited according to task demands. These components are not arranged in rigid systems, but they are neurally dissociable. Thus, this view can accommodate both the anatomic separability emphasized by the systems theorists and the importance of task analysis emphasized by processing theorists.

We believe that our view of taxonomy and theory reframes the memory systems debate and, indeed, suggests that researchers have been arguing about the wrong thing. The systems debate concerned whether or not memory is composed of multiple systems and pitted systems advocates versus processing advocates versus component processing advocates. We contend that all three camps used taxonomies in the wrong way: Systems advocates took taxonomic classes as theories, and researchers taking the other two positions did not make use of taxonomies at all.

This final point bears some reflection, however. Given the criticisms we have voiced over how classification of memory has been done in the past, is there a role for taxonomy in the study of memory? How should taxonomies be used in the study of memory?

\section{CAN TAXONOMIES OF MEMORY BE USEFUL?}

We have argued that taxonomies of memory cannot serve as theories of memory. We have also argued that the creation of a taxonomy requires making some assumptions about which features to include in the taxonomy. These assumptions will typically be guided by theory, and so taxonomy should be guided by theory, rather than a taxonomy serving to constrain theory.

We can fairly ask, therefore, is there any point to creating taxonomies of memory? We suggest that there is and that the history of cognitive psychology bears this conclusion out. We suggest that researchers of memory view taxonomies as they are viewed in biology: as organizational schemes for data that are descriptive rather than explana- 
tory. What can such taxonomies do, and how would they differ from what we have now?

\section{The Creation of Taxonomies}

Must memory researchers do something differently to create descriptive taxonomies? Yes, chiefly in terms of how they are evaluated. Researchers in other fields have described the procedures by which a taxonomy may be developed (Fleishman \& Quaintance, 1984; Mayr, 1942; Simpson, 1961). A minimum of four steps may be described.

First, a conceptual basis for the taxonomy must be selected. As discussed earlier, a single conceptual basis should be selected, or there is a probability that the taxonomy will not be internally consistent. Most existing classification systems of memory use more than one conceptual basis.

Second, a set of classes must be selected. The need for this step is self-evident. For example, if the conceptual basis is the anatomic substrate, one must select the anatomic classes into which individual memories might be classified (e.g., hippocampal, striatal, and cerebellar). In current classifications these classes have been called systems.

Third, the researcher must specify rules by which memories can be reliably assigned to one of the classes. Thus, the conceptual basis might be neuroanatomy, and the classes might be hippocampal, striatal, and cerebellar; the rule for classification might be that a memory is part of the "hippocampal" class if hippocampal damage compromises the memory. Alternatively, one could propose that the rule for classification be that the hippocampus normally participates in the memory (as determined by functional imaging) even if hippocampal damage does not compromise the memory. Such rules are necessary so that classification is objective. When different people use the taxonomy, the same classification should result.

Fourth, there must be a method of evaluating the taxonomy. We disagree with Tulving (2000), who suggests that there is not a way to evaluate the usefulness of ways of conceptualizing memory (such as taxonomies). We offer two criteria in evaluating taxonomies. First, the taxonomy must be internally consistent, meaning that it must afford classification of entities that is objective and unambiguous. Second, the taxonomy must be useful in inspiring theory. As described below, this does not mean that taxonomy will constrain theories. These two evaluative criteria are not currently the norm in the creation of memory system proposals, and so we examine them in more detail.

\section{Evaluating Taxonomies}

Internal consistency sounds unambiguously desirable. It simply means that entities can be reliably assigned to classes, so that two researchers working independently would classify new entities in the same way. Internal consistency may be at risk if the classes are theoretically sound, but the characteristics of entities are difficult to ascertain. For example, shared ancestral history is not a controversial principle on which to classify species, but it is diffi- cult to determine how closely related two species are, and, therefore, much effort goes into developing and evaluating methods of determining this characteristic (e.g., Crisci $\&$ Steussy, 1980; Stevens, 1980). In the case of memory, characteristics of memories may in some cases be unclear. For example, determining whether or not a memory relies on medial temporal lobe structures might entail assumptions about how to interpret lesion evidence or functional imaging evidence. Converging methods may help in such situations (e.g., Kosslyn \& Van Kleeck, 1990; Price, Mummery, Moore, Frackowiak, \& Friston, 1999); it should be noted that here we are talking about converging methods in service of identifying a single feature of a memory, as opposed to the expectation that different features will converge to help classify a memory.

Internal consistency can also be at risk when the characteristics of entities are easily determined but their relationship is not. For example, if physical characteristics define classes in a taxonomy of species, describing the characteristics is frequently not difficult, but organizing classes is not so straightforward. Evaluating the taxonomy becomes a job of determining whether the classes determined by physical characteristics are sensible. When applied to species, classification systems based solely on physical characteristics were criticized because there was no external criterion by which to evaluate whether the proposed classes made any sense (Johnson, 1970).

A rather more controversial consequence of setting internal consistency as a desideratum of taxonomies concerns the entities that are being classified. If a researcher seeks to define classes by characteristics that are hypothetical rather than directly observable (e.g., to define classes according to hypothetical cognitive processes), it is obviously much more difficult to be certain that a memory has that characteristic. For example, if a researcher defines a simple taxonomy of "nondeclarative" and "declarative" memory systems, what exactly is being classified? Memory traces? Memory processes? Either approach is workable, but, in that case, it is up to the researcher to describe unambiguous rules by which one can know when these processes or traces are invoked. In other words, if the taxonomy classifies entities that are not directly observable, the researcher must describe how these entities relate to entities that are observable.

The second component of evaluating taxonomies is evaluating whether the taxonomy is useful. Researchers of memory have taken "useful" to mean "accurately reflecting nature." That is, they have assumed that a good taxonomy is one that carves nature at the joints, but we have argued that nature does not have one set of joints. We propose that taxonomies can nevertheless prove useful and can do so by inspiring theory. As noted earlier, we do not believe that taxonomies can be used as de facto theories, nor can they constrain theories. Nevertheless, there are two ways that taxonomies can inspire theory.

Taxonomies can elucidate the inadequacy of current theory; in short, a taxonomy can surprise us. They do so by showing the regularity of some phenomenon that does not 
fit existing theory. The taxonomy rubs researchers' noses in a set of results, so to speak, demanding that the results be accounted for. The taxonomy does not point the way to an account for these results. The taxonomy need not point to an obvious variable or set of variables missing from current theories that would account for a large portion of variance in the data, although this is another useful function of taxonomies. The taxonomy merely points up the need for better theory. An example of this sort of taxonomy was the distinctionbetween short-term and long-term memory. Similar distinctions go back to at least to James (1890), but it was not until the late 1950s and early 1960 s that a flurry of results were produced that seemed inconsistent with the then-current understanding of memory, chiefly in the mechanism of forgetting (Broadbent, 1958; Brown, 1958; Peterson \& Peterson, 1959). It seemed unlikely that the loss of information after a delay as brief as $30 \mathrm{sec}$ could be due to interference; it seemed much more likely that it was due to decay. But memory theories at the time held that forgetting was caused primarily by interference. Thus, it seemed plausible that two different mechanisms were at work: short-term memory, in which forgetting was caused by decay, as opposed to long-term memory, in which forgetting was due to interference.

It is interesting to note the parallels in the short-term/ long-term memory literature and the nondeclarative/declarative literature. The short-term/long-term literature began with a simple difference between two putative types of memory: Memories less than $30 \mathrm{sec}$ in duration were forgotten due to decay, whereas memories of longer duration were forgotten due to interference (Brown, 1958). There was considerable effort to find other differences: for example, differences in representations (Baddeley, 1966; Conrad \& Hull, 1964), differences in neural basis (Baddeley \& Warrington, 1970; Shallice \& Warrington, 1970), and so on. Researchers found support for some of the distinctions and discovered that some of the differences that had been reported were in error (including the initial difference in cause of forgetting; Keppel \& Underwood, 1962). Critics argued that there was no distinction to be made and that there was one memory system (Melton, 1963; Wickelgren, 1973).

For some researchers, the taxonomic distinction between short-term and long-term memory was not sufficient to convince them that the distinction was real. Only when more detailed theories of short-term memory (then working memory) were proposed that could account for much of the extant data and make new predictions (e.g., Baddeley \& Hitch, 1974) were virtually all researchers convinced that the distinction between short-term and long- term memory was valuable. The initial taxonomic distinction was not completely compelling to all, but it was essential nevertheless, because it got researchers interested in and enthusiastic about the idea. The taxonomy gave impetus to the data that eventually drove the development of the theory.

Why do we suggest that the initial distinction between short-term and long-term memory was, indeed, a taxon- omy? Couldn't it simply be called a poorly developed theory, to be replaced by better developed (and therefore more convincing) theories? The initial proposals were taxonomies because they were descriptive. They categorized memories based on their features: Memories were forgotten after a minute of distraction, or they were not; memories were represented in an acoustic code or a semantic code. Taxonomies are descriptive, not predictive. Taxonomies can generate predictions only if the taxonomy defines classes along multiple features. Taxonomies can also generate what we might call collateral predictions: Given that we believe that forgetting occurs in short-term memory via decay, we might derive another prediction about the behavioral manifestation of decay.

The nondeclarative/declarative distinction is following the same course. The initial proposal was based on an anatomic dissociation and on a dissociation of one characteristic in intact subjects-a dissociation of consciousness. There has been a good deal of effort toward discerning other characteristics on which nondeclarative and declarative memories differ, including differences in the specificity of the retrieval conditions (Dienes \& Berry, 1997; Tulving \& Schacter, 1990) and the composibility of the memory (Cohen, Poldrack, \& Eichenbaum, 1997), but these differences have been questioned (Stadler, 1997; Willingham, 1997, 1998). In addition, some critics have questioned whether a distinction between nondeclarative and declarative is necessary (Perruchet \& Amorim, 1992; Shanks \& St. John, 1994), just as people questioned whether the distinction between short-term and long-term memory is necessary. Again, taxonomic distinctions have not been enough to persuade all researchers of the distinction's validity. A successful theory may convince them, and, in the last 10 years, there have been increasing efforts toward theories that encompass nondeclarative and declarative memory (e.g., Cohen \& Eichenbaum, 1993; Metcalfe, Cottrell, \& Mencl, 1992), but a theory that is as widely accepted as the working memory model has not been proposed.

We suggest that, in the case of the nondeclarative/declarative distinction, taxonomy was useful in surprising researchers and in encouraging them to explore new areas of learning and memory. On the other hand, taxonomy has done its job in the nondeclarative/declarative distinction and has taken us as far as it can. Taxonomies cannot and should not convince researchers that the distinction is correct, but they can (and did) draw researchers' attention to the fact that our definition of memory was too narrow and that there were ways in which experience changes human behavior that were not being studied. These different types of memory demand explanation, whether or not nondeclarative/declarative ends up being an important theoretical distinction. We believe that the episodic/semantic distinction (Tulving, 1972, 1983) served the same purpose, a point that Tulving, the initiator of the distinction, has made in some contexts (Tulving, 1986).

In addition to elucidating the inadequacy of current theory, there is a second way that taxonomies can be useful. 
They can provide a systematic organization of data that points to empirical distinctions that account for considerable variance. A taxonomy can highlight task characteristics, or it can highlight the ways that behavior changes across tasks.

An example of such a taxonomy is the propositional/ analogue distinction (Kosslyn, 1980). The initial observation was a simple association between task characteristics and behavior: When a task demanded that a participant make a judgment about the visual appearance of an object that was not present, or the object's appearance once spatially transformed (e.g., rotated), participants reliably reported experiencing visual images (e.g., Shepard \& Metzler, 1971). This observation led researchers to test another association between task characteristics and behavior: Spatial characteristics of the tasks would be reflected in behavior just as they would be in the physical world. For example, increasing the distance to be scanned or rotated would increase the time it takes to accomplish the scan or rotation (Kosslyn, Ball, \& Reiser, 1978).

When these predictions were confirmed, researchers had in hand a simple taxonomy of tasks: those that reliably led to imagery and those that did not, and each type of task was associated with a small set of behaviors. This taxonomy was useful not because it was surprising but because it showed regularity in a set of tasks that pointed toward an important distinction. The taxonomy made it appear likely that one could draw a theoretical distinction between spatial and nonspatial representations. This insight does not constrain theory-it does not restrict the space of theories that could possibly account for the data-but rather points to a particular variable that appears promising for inclusion in a theory.

Just as in the nondeclarative/declarative and shortterm/long-term debates, the initial taxonomic distinction drew criticism-chiefly, that it was unnecessary (Pylyshyn, 1973, 1981). And, again, although the taxonomy did not convince all psychologists of the psychological reality of the distinction, it did inspire more detailed theories (Kosslyn, 1980) that researchers found convincing.In this case, the need for specific theories was made particularly salient by a call for more detailed theories by Anderson (1978).

In summary, we suggest that taxonomies can be useful in cognitive psychology, and, indeed, history indicates that they have been useful. They can be useful in surprising us by pointing toward an area of memory for which current theory cannot account, and they can be useful by pointing to distinctions in tasks that account for substantial variance in behavior (i.e, by exposing regularity). Taxonomies may point up the need for further investigation of understudied domains, as in the nondeclarative/declarative distinction and the short-term/long-term distinction. Taxonomies may provide rather general guidance for theories, as in the propositional/analogue distinctions. In both cases, the value of taxonomies lies in their ability to inspire, rather than to persuade.

\section{CRITICISMS REVISITED}

It is worth noting that most of the criticisms leveled against multiple memory systems proposals do not apply to taxonomies that are meant only to be descriptive.

Some criticisms centered on the data-specifically on the possibility that amnesic patients might be somewhat impaired in learning nondeclarative tasks and that neurologically intact participants might show some awareness of what was supposed to be nondeclarative knowledge. These criticisms amount to statements that the features distinguishing nondeclarative and declarative memory are quantitative, not qualitative: Declarative memory is devastated by hippocampal damage, and nondeclarative memory is somewhat impaired, although not devastated, according to the critics. In the case of neurologically intact participants, the criticism is that declarative memory is reliably and robustly accessible to awareness, whereas nondeclarative memory is not completely cloaked to awareness as claimed but rather gains some shaded, incomplete access.

This argument assumes that the differences between nondeclarative and declarative memory must be categorical to be meaningful, as shown in Figure 3A; either the hippocampus contributes or it does not. That might be true if nondeclarative and declarative are to describe systems, but it need not be true in a taxonomy. Taxonomic distinctions can be based on any attribute that has a bimodal distribution, as shown in Figure 3B. It is true that the distribution must be bimodal to support a categorical distinction. After all, sorting entities into groups assumes that there are indeed groups into which they can be sorted. If a characteristic is distributed unimodally (Figure 3C), there are not clear groups based on this characteristic, and no information is gained by dividing entities into groups; one has simply described an arbitrary cutoff of the dimension and added labels. One could apply a dimensional model instead of a categorical one, an approach that has not been utilized in memory systems.

A second criticism was that distinctions such as nondeclarative/declarative are circular, because they are defined after the fact, once some of the memory's attributes are known. For example, one might think a task is supported by the nondeclarative system, only to discover that amnesic patients are impaired in performing the task, and so conclude that the declarative system makes some contribution to the task. Again, such a practice might be inappropriate if the nondeclarative/declarative distinction were to serve as an explanatory theory. If it is to serve as a descriptive taxonomy, it is appropriate; one classifies an object by identifying its attributes. If the critical attribute of a taxonomic category is whether or not it is intact in amnesia, then one must ascertain the value of that attribute before the memory can be classified.

Another criticism of the multiple memory systems enterprise is the faultiness of dissociation techniques such as functional dissociation and stochastic independence. Some have pointed out that dissociations are so easy to 

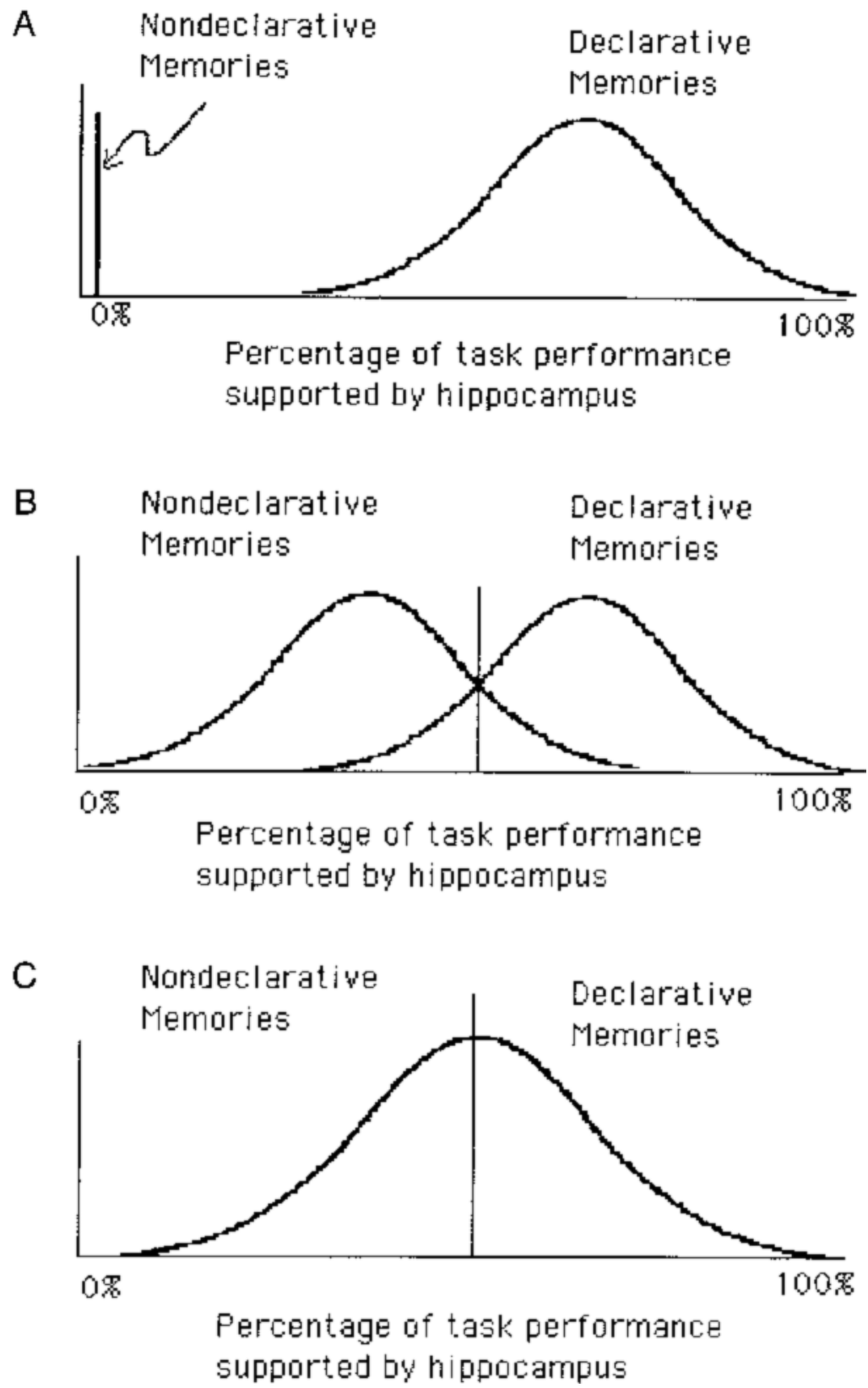

Figure 3. Hypothetical distributions of features and what they mean to a taxonomy. A feature need not have two distinct distributions (shown in Panel A) for it to be useful to a taxonomy. So long as the distribution of a feature is bimodal (as in Panel B), it may be useful to a taxonomy. If a feature is distributed normally (as in Panel C), the feature is not useful for a taxonomy.

obtain that they lead one to conclude that recognition and recall constitute separate memory systems (Roediger et al., 1999; Weldon, 1999). Although one might argue that recognition and recall might indeed be separate systems, this is certainly not what the proponents of these dissociation techniques envisioned. To put it another way, one might offer the friendly challenge: Where are the tasks that do not dissociate from one another, so that we can conclude that they tap the same memory system?

Although we think that these dissociation techniques are weak, the fact is that they are not really relevant to the development of taxonomies as we have described them. These dissociation techniques were put forward to identify separate systems, not to identify taxonomic classes. 
We maintain that they do not identify separate memory systems, but they should be irrelevant to the development of a memory taxonomy.

Critics have also charged that the systems enterprise can easily run wild and yield too many memory systems; the explanatory power of the multiple systems perspective is lost if the response to each new puzzling result is to propose a new memory system. Memory systems advocates proposed using multiple criteria (i.e., multiple conceptual bases) as a way of ensuring that there would not be too many systems. We have argued that it is critical to use a single conceptual basis in creating a taxonomy. Is it not possible that this practice will result in too many classes of memory in a taxonomy? That result is not at all inevitable. Stating that the critical attributes of a taxonomy are neuroanatomic does not mean that every neuroanatomic attribute must be critical. Similarly, a taxonomy of species may use physical characteristics to distinguish species, but that does not mean that all physical characteristics are used to distinguish classes; a German Shepard that is mostly black and a German Shepard that is mostly tan still belong in the same class.

Finally, critics have noted that anatomic differences do not compel cognitive differences. We agree, and, again, we emphasize that taxonomy should inspire. It should not be taken as a set of rules that compels theory to hold a certain form.

In sum, the criticisms leveled against classification systems that were treated as theories do not apply to taxonomies.

\section{CONCLUSION}

There has not been a clear resolution to the memory systems debate. We have argued that this is so because two assumptions have been made in this literature. In developing taxonomies, researchers have assumed that features of memory will be correlated across conceptual bases. Using biological systematics as a guide, we argue that this assumption is unlikely to be correct, and indeed there are already data in the memory literature indicating that it is not correct. In evaluating taxonomies, researchers have assumed that the mapping from taxonomy to theory will be one-to-one. Again using biological systematics as an example, we argue that this assumption is unwarranted and probably wrong. The relationship of theory and taxonomy can be complex, and more important, theory must precede taxonomy, so taxonomies cannot be used to constrain theories.

Does that mean that if these two assumptions were not made that the memory systems debate would be resolved? It would be, but not in the way that researchers likely expect. The memory systems debate would be resolved by concluding that much of the debate has been misguided. Researchers have argued about the existence of multiple memory systems (a theoreticalquestion) based on the development of taxonomies (which are not theories, but are organizations of data). Perhaps without recognizing that they were doing so, systems advocates have argued for the adoption of taxonomies as theories, and processing advocates have argued for the expulsion of taxonomies from the study of memory. We argue that the memory systems debate was bound to go unresolved so long as researchers made the two key assumptions that we described. We also argue that the resolution of the memory systems debate is at hand, and the resolution is to take taxonomies for what they are-organized descriptions of data that may prove useful in inspiring theories.

Taxonomies cannot constraint theory-that is, they cannot set boundaries in which theories must operate. They can, however, inspire theory by directing attention toward an area of memory for which current theory cannot account, or by pointing to distinctions in tasks that account for substantial variance in behavior. Avoiding the problems in taxonomy while gaining the potential benefits relies on treating taxonomies as useful organizational schemes of data, not explanations for data.

\section{REFERENCES}

Anderson, J. R. (1978). Arguments concerning representations for mental imagery. Psychological Review, 85, 249-277.

BADDELEY, A. D. (1966). The capacity for generating information by randomization. Quarterly Journal of Experimental Psychology, 18, 119129.

Baddeley, A. D., \& Hitch, G. J. (1974). Working memory. In G. H. Bower (Ed.), The psychology of learning and motivation (Vol. 8, pp. 47-90). New York: Academic Press.

BadDeley, A. D., \& Warrington, E. K. (1970). Amnesia and the distinction between long- and short-term memory. Journal of Verbal Learning \& Verbal Behavior, 9, 176-189.

BAum, D. A., \& LARson, A. (1991). Adaptation reviewed: A phylogenetic methodology for studying character macroevolution. Systematic Zoology, 40, 1-18.

BLAXTON, T. A. (1989). Investigating dissociation among memory measures: Support for a transfer-appropriate processing framework. Journal of Experimental Psychology: Learning, Memory, \& Cognition, 15, 657-668.

Blaxton, T. A. (1999). Combining disruption and activation techniques to map conceptual and perceptual memory processes in the human brain. In J. K. Foster \& M. Jelicic (Eds.), Memory: Structure, function, or process? (pp. 104-129). Oxford: Oxford University Press.

Brady, R. H. (1985). On the independence of systematics. Cladistics, $\mathbf{1}$, 113-126.

Broadbent, D. E. (1958). Perception and communication. Oxford: Oxford University Press.

Brown, J. (1958). Some tests of the decay theory of immediate memory. Quarterly Journal of Experimental Psychology, 10, 12-21.

Cermak, L. S., \& Reale, L. (1978). Depth of processing and retention of words by alcoholic Korsakoff patients. Journal of Experimental Psychology: Human Learning \& Memory, 4, 165-174.

Challis, B. H., \& Brodbeck, D. R. (1992). Level of processing affects priming in word fragment completion. Journal of Experimental Psychology: Learning, Memory, \& Cognition, 18, 595-607.

Chun, M. M., \& Phelps, E. A. (1999). Memory deficits for implicit contextual information in amnesic subjects with hippocampal damage. Nature Neuroscience, 2, 844-847.

Cohen, N. J., \& Eichenbaum, H. (1993). Memory, amnesia, and the hippocampal system. Cambridge, MA: MIT Press.

Cohen, N. J., Poldrack, R A., \& Eichenbaum, H. (1997). Memory for items and memory for relations in the procedural/declarative memory framework. Memory, 5, 131-178. 
Cohen, N. J., \& Squire, L. R. (1980). Preserved learning and patternanalyzing skill in amnesia: Dissociation of knowing how and knowing that. Science, 210, 207-210.

Conrad, R., \& Hull, A. J. (1964). Information, acoustic confusion and memory span. British Journal of Psychology, 55, 429-432.

CORKIN, S. (1968). Acquisition of motor skill after bilateral medial temporal lobe excision. Neuropsychologia, 6, 255-265.

Craik, F. I., \& Tulving, E. (1975). Depth of processing and the retention of words in episodic memory. Journal of Experimental Psychology: General, 104, 268-294.

CRISCI, J. V., \& Steussy, T. F. (1980). Determining primitive character states for phylogenetic reconstruction. Systematic Botany, 5, 112 135.

DE PINNA, M. C. (1991). Concepts and tests of homology and the cladistic paradigm. Cladistics, 7, 367-394.

Dienes, Z, \& Berry, D. (1997). Implicit learning: Below the subjective threshold. Psychonomic Bulletin \& Review, 4, 3-23.

DunN, J. C., \& KIRSNER, K. (1988). Discovering functionally independent mental processes: The principle of reversed association. Psychological Review, 95, 91-101.

EstaBROOK, G. F. (1972). Cladistic methodology: A discussion of the theoretical basis for the induction of evolutionary history. Annual Review of Ecology \& Systematics, 3, 427-456.

Fleishman, E. A., \& Quaintance, M. K. (1984). Taxonomics of human performance. Orlando, FL: Academic Press.

Foster, J. K., \& Jelicic, M. (1999). Memory: Systems, process, or function? Oxford: Oxford University Press.

Gabrieli, J. D. E. (1998). Cognitive neuroscience of human memory. Annual Review of Psychology, 49, 87-115.

GABRIELI, J. D. E. (1999). The architecture of human memory. In J. K. Foster \& M. Jelicic (Eds.), Memory: Structure, function, or process? (pp. 205-231). Oxford: Oxford University Press.

GraF, P., \& Schacter, D. L. (1985). Implicit and explicit memory for new associations in normal and amnesic subjects. Journal of Experimental Psychology: Learning, Memory, \& Cognition, 11, 501-518.

Graf, P., Squire, L. R. \& Mandler, G. (1984). The information that amnesic patients do not forget. Journal of Experimental Psychology: Learning, Memory, \& Cognition, 10, 164-178.

Green, R. E. A., \& Shanks, D. R. (1993). On the existence of independent explicit and implicit learning systems: An examination of some evidence. Memory \& Cognition, 21, 304-317.

Hayes, B. K., \& Hennessy, R. (1996). The nature and development of nonverbal implicit memory. Journal of Experimental Child Psychology, 63, 22-43.

Heindel, W. C., Salmon, D. P., Shults, C. W., Walicke, P. A., \& ButTERS, N. (1989). Neuropsychological evidence for multiple implicit memory systems: A comparison of Alzheimer's, Huntington's, and Parkinson's disease patients. Journal of Neuroscience, 9, 582-587.

HeNNIG, W. (1966). Phylogenetic systematics. Urbana: University of Illinois Press.

Hintzman, D. L. (1990). Human learning and memory: Connections and dissociations. Annual Review of Psychology, 41, 109-140.

Hirst, W. (1982). The amnesic syndrome: Descriptions and explanations. Psychological Bulletin, 91, 435-460.

Howe, M. L., Rabinowitz, F. M., \& GRANT, M. J. (1993). On measuring (in)dependence of cognitive processes. Psychological Review, $\mathbf{1 0 0}$ 737-747.

Huppert, F. A., \& Piercy, M. (1982). In search of the functional locus of amnesic syndromes. In L. S. Cermak (Ed.), Human memory and amnesia (pp. 123-137). Hillsdale, NJ: Erlbaum.

JACOBY, L. L., \& Dallas, M. (1981). On the relationship between autobiographical memory and perceptual learning. Journal of Experimental Psychology: General, 110, 306-340.

JAMES, W. (1890). Principles of Psychology. New York: Holt.

Johnson, L.A.S. (1970). Rainbow's end: The quest for an optimal taxonomy. Systematic Zoology, 19, 203-239.

Keane, M. M., Gabrieli, J. D. E, Fenneman, A. C., Growdon, J. H., \& CoRKIN, S. (1991). Evidence for a dissociation between perceptual and conceptual priming in Alzheimer's disease. Behavioral Neuroscience, 105, 326-342.

KePPEL, G., \& Underwood, B. J. (1962). Proactive inhibition in short- term retention of single items. Journal of Verbal Learning \& Verbal Behavior, 1, 153-161.

KNOPMAN, D. (1991). Unaware learning versus preserved learning in pharmacologic amnesia: Similarities and differences. Journal of Experimental Psychology: Learning, Memory, \& Cognition, 17, 1017-1029.

Kolers, P. A., \& Roediger, H. L., III (1984). Procedures of mind. Journal of Verbal Learning \& Verbal Behavior, 23, 425-449.

KossLYN, S. M. (1980). Image and mind. Cambridge, MA: Harvard University Press.

Kosslyn, S. M., Ball, T. M., \& Reiser, B. J. (1978). Visual images preserve metric spatial information: Evidence from studies of image scanning. Journal of Experimental Psychology: Human Perception \& Performance, 4, 47-60.

Kossly n, S. M., \& VAn KleEcK, M. (1990). Broken brains and normal minds: Why humpty-dumpty needs a skeleton. In E. Schwartz (Ed.), Computational neuroscience (pp. 390-402). Cambridge, MA: MIT Press.

Maslin, T. P. (1952). Morphological criteria of phyletic relationships. Systematic Zoology, 1, 49-70.

MAY R, E. (1942). Systematics and the origin of species. New York: Columbia University Press.

May R, E. (1969). Principles of systematic zoology. New York: McGrawHill.

McKoon, G., \& RATCLIFF, R. (1995). How should implicit memory phenomena be modeled? Journal of Experimental Psychology: Learning, Memory, \& Cognition, 21, 777-784.

Melton, A. W. (1963). Implications of short-term memory for a general theory of memory. Journal of Verbal Learning \& Verbal Behavior, 2, $1-21$

Metcalfe, J., Cottrell, G. W., \& Mencl, W. E. (1992). Cognitive binding: A computational-modeling analysis of a distinction between implicit and explicit memory. Journal of Cognitive Neuroscience, 4, 289-298.

Moscovitch, M. (1994). Memory and working with memory: Evaluation of a component process model and comparisons of other models. In D. L. Schacter \& E. Tulving (Eds.), Memory systems 1994 (pp. 269310). Cambridge, MA: MIT Press.

Moscovitch, M., \& UmiLtà, C. (1991). Conscious and nonconscious aspects of memory: A neuropsychological framework of modules and central systems. In. R. G. Lister \& H. J. Weingartner (Eds.), Perspectives in cognitive neuroscience (pp. 229-266). Oxford: Oxford University Press.

NADEL, L. (1994). Multiple memory systems: What and why, an update. In D. L. Schacter \& E. Tulving (Eds.), Memory systems 1994 (pp. 3963). Cambridge, MA: MIT Press.

NAITO, M. (1990). Repetition priming in children and adults: Age-related dissociation between implicit and explicit memory. Journal of Experimental Child Psychology, 50, 462-484.

NeEly, J. H. (1989). Experimental dissociations and the episodic/semantic memory distinction. In H. L. Roediger III \& F. I. M. Craik (Eds.), Varieties of memory and consciousness: Essays in honour of Endel Tulving (pp. 229-270). Hillsdale, NJ: Erlbaum.

Nissen, M. J., Willingham, D. B., \& Hartman, M. (1989). Explicit and implicit remembering: When is learning preserved in amnesia? Neuropsychologia, 27, 341-352.

Nyberg, L., \& Tulving, E. (1996). Classifying human long-term memory: Evidence from converging dissociations. European Journal of Cognitive Psychology, 8, 163-183.

O'KEEFE, J., \& NADEL, L. (1978). The hippocampus as a cognitive map. Oxford: Oxford University Press, Clarendon Press.

Olton, D. S. (1989). Inferring psychological dissociations from experimental dissociations: The temporal context of episodic memory. In H. L. Roediger III \& F. I. M. Craik (Eds.), Varieties of memory and consciousness: Essays in honour of Endel Tulving (pp. 161-176). Hillsdale, NJ: Erlbaum.

OstergaArd, A. L. (1999). Priming deficits in amnesia: Now you see them, now you don't. Journal of the International Neuropsychological Society, 5, 175-190.

OstergaArd, A. L., \& Jernigan, T. L. (1993). Are word priming and explicit memory mediated by different brain structures? In P. Graf \& M. Masson (Eds.), Implicit memory: New directions in cognition, development, and neuropsychology (pp. 327-349). Hillsdale, NJ: Erlbaum. 
Perruchet, P., \& Amorim, M.-A. (1992). Conscious knowledge and changes in performance in sequence learning: Evidence against dissociation. Journal of Experimental Psychology: Learning, Memory, \& Cognition. 18, 785-800.

Perruchet, P., Bigand, E., \& Benoit-Gonin, F. (1997). The emergence of explicit knowledge during the early phase of learning in sequential reaction time tasks. Psychological Research, 60, 4-13.

Peterson, L., \& Peterson, M. J. (1959). Short-term retention of individual items. Journal of Experimental Psychology, 58, 193-198.

Platnick, N. I. (1980). Philosophy and the transformation of cladistics. Systematic Zoology, 28, 537-546.

PoldRACK, R. A (1996). On testing for stochastic dissociations. Psychonomic Bulletin \& Review, 3, 434-448.

Price, C. J., Mummery, C. J., Moore, C. J., Frackowiak, R. S. J., \& Friston, K. J. (1999). Delineating necessary and sufficient neural systems with functional imaging studies of neuropsychological patients. Journal of Cognitive Neuroscience, 11, 371-382.

Pylyshyn, Z W. (1973). What the mind's eye tells the mind's brain: A critique of mental imagery. Psychological Bulletin, 80, 1-24.

Pylyshyn, Z W. (1981). The imagery debate: Analogue media versus tacit knowledge. Psychological Review, 88, 16-45.

Ratcliff, R., \& McKoon, G. (1995). Bias in the priming of object decisions. Journal of Experimental Psychology: Learning, Memory, \& Cognition, 21, 754-767.

Ratcliff, R. \& McKoon, G. (1996). Bias effects in implicit memory tasks. Journal of Experimental Psychology: General, 125, 403-421.

Reber, P. J., \& Squire, L. R. (1994). Parallel brain systems for learning with and without awareness. Learning \& Memory, 1, 217-229.

RIDLEY, M. (1986). Evolution and classification. London: Longman.

Robisns, T. W. (1996). Refining the taxonomy of memory. Science, 273, 1353-1354.

Roediger, H. L., III (1990). Implicit memory: A commentary. Bulletin of the Psychonomic Society, 28, 373-380.

Roediger, H. L., III, Buckner, R., \& McDermott, K. B. (1999). Components of processing. In J. K. Foster \& M. Jelicic (Eds.), Memory: Structure, function, or process? (pp. 31-65). Oxford: Oxford University Press.

Roediger, H. L., III, Rajaram, S., \& Srinivas, K. (1990). Specifying criteria for postulating memory systems. In A. Diamond (Ed.), The development and neural bases of higher cognitive function (Annals of the New York Academy of Sciences, Vol. 608, pp. 572-595). New York: New York Academy of Sciences.

Russo, R., Nichelli, P., Gibertoni, M., \& Cornia, C. (1995). Developmental trends in implicit and explicit memory: A picture completion study. Journal of Experimental Child Psychology, 59, 566-578.

SCHACTER, D. L. (1987). Implicit memory: History and current status. Journal of Experimental Psychology: Learning, Memory, \& Cognition, 13, 501-518.

SCHACTER, D. L. (1992). Understanding implicit memory: A cognitive neuroscience approach. American Psychologist, 47, 559-569.

SCHACTER, D. L., \& COOPER, L. A. (1995). Bias in the priming of object decisions: Logic, assumption, and data. Journal of Experimental Psychology: Learning, Memory, \& Cognition, 21, 768-776.

Schacter, D. L., \& Tulving, E. (1994a). Memory systems 1994. Cambridge, MA: MIT Press.

Schacter, D. L., \& Tulving, E. (1994b). What are the memory systems of 1994? In D. L. Schacter \& E. Tulving (Eds.), Memory systems 1994 (pp. 1-38). Cambridge, MA: MIT Press.

Schacter, D. L., Wagner, A. D., \& Buckner, R. L. (2000). Memory systems of 1999. In E. Tulving \& F. I. M. Craik (Eds.), The Oxford handbook of memory (pp. 627-643). Oxford: Oxford University Press.

Shallice, T., \& Warrington, E. K. (1970). Independent functioning of verbal memory stores: A neuropsychological study. Quarterly Journal of Experimental Psychology, 22, 261-273.

Shanks, D. R., \& Johnstone, T. (1999). Evaluating the relationship between explicit and implicit knowledge in a sequential reaction time task. Journal of Experimental Psychology: Learning, Memory, \& Cognition, 25, 1435-1451.

Shanks, D. R., \& St. John, M. F. (1994). Characteristics of dissociable learning systems. Behavioral \& Brain Sciences, 17, 367-447.
Shepard, R. N., \& Metzler, J. (1971). Mental rotation of three-dimensional objects. Science, 171, 701-703.

Sherry, D. F., \& Schacter, D. L. (1987).The evolution of multiple memory systems. Psychological Review, 94, 439-454.

Shimamura, A. P. (1985). Problems with the finding of stochastic independence as evidence for multiple memory systems. Bulletin of the Psychonomic Society, 23, 506-508.

Simpson, G. G. (1961). Principles of animal taxonomy. New York: Columbia University Press.

Sneath, P. H. A., \& Sokal, R. R. (1973). Numerical taxonomy. San Francisco: W. H. Freeman.

SOKAL, R. R., \& SNEATH, P. H. A. (1963). The principles of numerical taxonomy. San Francisco: W. H. Freeman.

SQuire, L. R. (1992). Memory and the hippocampus: A synthesis from findings with rats, monkeys, and humans. Psychological Review, 99, 195-231.

Squire, L. R., \& Zola-Morgan, S. (1991). The medial temporal lobe memory system. Science, 253, 1380-1386.

StadLer, M. A. (1997). Distinguishing implicit and explicit learning. Psychonomic Bulletin \& Review, 4, 56-62.

Stern, L. D. (1981). A review of theories of human amnesia. Memory \& Cognition, 9, 247-262.

Stevens, P. F. (1980). Evolutionary polarity of character states. Annual Review of Ecology \& Systematics, 11, 333-358.

Tотн, J. P., \& Hunt, R. R. (1999). Not one versus many, but zero versus any: Structure and function in the context of the multiple-memory systems debate. In J. K. Foster \& M. Jelicic (Eds.), Memory: Structure, function, or process? (pp. 232-272). Oxford: Oxford University Press.

Tulving, E. (1972). Episodic and semantic memory. In E. Tulving \& W. Donaldson (Eds.), Organization and memory (pp. 382-403). New York: Academic Press.

Tulving, E. (1983). Elements of episodic memory. Oxford: Oxford University Press.

Tulving, E. (1984). How many memory systems are there? American Psychologist, 40, 385-398.

Tulving, E. (1985). On the classification problem in learning and memory. In L.-G. Nilsson \& T. Archer (Eds.), Perspectives on learning and memory (pp. 67-94). Hillsdale, NJ: Erlbaum.

Tulving, E. (1986). What kind of a hypothesis is the distinction between episodic and semantic memory? Journal of Experimental Psychology: Learning, Memory, \& Cognition, 12, 307-311.

Tulving, E. (1999). Study of memory: Processes and systems. In J. K. Foster \& M. Jelicic (Eds.), Memory: Structure, function, or process? (pp. 11-30). Oxford: Oxford University Press.

Tulving, E. (2000). Concepts of memory. In E. Tulving \& F. I. M. Craik (Eds.), The Oxford handbook of memory (pp. 33-43). Oxford: Oxford University Press.

Tulving, E., \& Schacter, D. L. (1990). Priming and human memory systems. Science, 247, 301-306.

Tulving, E., Schacter, D. L., \& Stark, H. A. (1982). Priming effects in word-fragment completion are independent of recognition memory. Journal of Experimental Psychology: Learning, Memory, \& Cognition, 8, 336-342.

Warrington, E. K., \& Weiskrantz, L. (1970). Amnesia: Consolidation or retrieval? Nature, 228, 628-630.

WELDON, M. S. (1999). The memory chop shop: Issues in the search for memory systems. In J. K. Foster \& M. Jelicic (Eds.), Memory: Structure, function, or process? (pp. 162-204). Oxford: Oxford University Press.

Wickelgren, W. A. (1973). The long and short of memory. Psychological Bulletin, 80, 425-438.

Wiley, E. O., Siegel-Causey, D., Brooks, D. R., \& Funk, V. A (1991). The compleat cladist: A primer of phylogenetic procedures (Spec. Pub. No. 19). Lawrence: University of Kansas Museum of Natural History.

Willingham, D. B. (1997). Implicit and explicit memory do not differ in flexibility: Comment on Dienes and Berry (1997). Psychonomic Bulletin \& Review, 4, 587-591.

Willingham, D. B. (1998). What differentiates declarative and procedural memory: Reply to Cohen, Poldrack, and Eichenbaum (1997). Memory, 6, 689-699. 
Winocur, G. (1982). The amnesic syndrome: A deficit of cue utilization. In L. S. Cermak (Ed.), Human memory and amnesia (pp. 139166). Hillsdale, NJ: Erlbaum.

\section{NOTES}

1. We use the term multiple memory systems proposals to imply neither a theory of memory nor a taxonomy of memory. There has been some confusion as to whether extant proposals are theories or taxonomies-a point we take up later in the paper. We take theories to be explanatory and taxonomies to be purely descriptive. We use the term multiple memory systems proposals as a neutral term.

2. A notable exception is Graf and Schacter's (1985) implicit/explicit distinction, which they proposed as a dichotomy of tasks and which they pointed out need not refer to memory systems.

(Manuscript received December 15, 2000; revision accepted for publication June 14, 2001.) 